\title{
Pollution and respiratory morbidity: how much do we accept?
}

\author{
J Britton
}

Exposure to atmospheric pollution is an unavoidable if unwelcome consequence of life in modern industrialised society. The adverse effects of particulate air pollution have been recognised since the London smogs of the early 1950s. ${ }^{1}$ Although the introduction of pollution controls in many countries have substantially reduced atmospheric particulate pollution, the effects of existing ambient pollution with smoke, ozone, sulphates, and nitrates have continued to attract interest. ${ }^{2-11}$ Two studies published recently in the American Journal of Epidemiology indicate that exposure to pollutants at the current usual and permitted levels is associated with increased respiratory morbidity. The first of these, by Sunyer et $a l,{ }^{12}$ investigated the association between ambient atmospheric pollution by sulphur dioxide, nitrogen dioxide, black smoke, carbon monoxide, and ozone on emergency room attendances for chronic obstructive lung disease in adults in Barcelona. The second, by Neas and colleagues, ${ }^{13}$ studied the relation between indoor nitrogen dioxide pollution and respiratory symptoms in children.

In the Barcelona study ${ }^{12}$ daily arithmetic average sulphur dioxide and black smoke concentrations and one hour maximum sulphur dioxide, nitrogen dioxide, carbon monoxide, and ozone concentrations were obtained from 17 sites in the city for two years, in conjunction with meteorological data on maximum and minimum temperature, wind speed, relative humidity, and barometric pressure. Details of emergency room admissions were obtained from the four largest hospitals in Barcelona, which see approximately $90 \%$ of all respiratory emergencies within the city. Chronic obstructive lung disease was defined as any mention of chronic bronchitis, emphysema, chronic airways obstruction, cor pulmonale, or bronchoconstriction, or acute respiratory failure secondary to these conditions. Asthma was not included in the category of chronic obstructive lung disease.

During the study period average daily sulphur dioxide and black smoke concentrations did not exceed current European Community limits ${ }^{14}$ at any stage. Hourly maximum values for black smoke exceeded the World Health Organisation air quality guidelines ${ }^{15}$ on $19 \%$ of days, sulphur dioxide on $4 \%$ of days, and nitrogen dioxide, carbon monoxide, and ozone each on less than $1 \%$ of days. Emergency room admissions with chronic obstructive lung disease were significantly related to daily average sulphur dioxide and black smoke and to hourly maximum sulphur dioxide and carbon monoxide, but not to hourly maximum nitrogen dioxide. Admissions for chronic obstructive lung disease were inversely related to ozone concentrations. The associations with sulphur dioxide, black smoke and carbon monoxide remained significant after adjustment for meteorological variables, season, and day of the week. The effect of sulphur dioxide also remained significant and of similar magnitude if the analysis was restricted to days on which sulphur dioxide concentrations were below the World Health Organisation guideline of $100 \mu \mathrm{g} / \mathrm{m}^{3}$, and of similar magnitude though not significant when restricted to days below $72 \mu \mathrm{g}$. The effect of sulphur dioxide was about 0.5 admissions a day per $25 \mu \mathrm{g} / \mathrm{m}^{3}$ (one standard deviation of change), and the effect of black smoke and carbon monoxide about 0.4 admissions a day per standard deviation of change. This was small in relation to the total number of daily admissions, which averaged 11.9 , and was also smaller than the effects of minimum temperature, day of the week, and season. Sulphur dioxide appeared to have more effect when temperatures were high, but interactions between the effects of pollutants were not explored.

The study by Neas et $a l^{13}$ used a much simpler design, which was in essence a cross sectional analysis of the relation between average indoor nitrogen dioxide concentrations, measured in the child's home, and the reporting of respiratory symptoms and the level of pulmonary function in the child. The sample comprised 1567 children aged 7-11 years, and was stratified to control for confounding by passive smoking. Average nitrogen dioxide concentrations in homes with a major source of nitrogen dioxide (defined as a gas cooking stove or kerosene heater) were $15 \mathrm{ppb}$ higher than in homes without a major source. After adjustment for smoking, age, and other potential confounders, a difference in average indoor nitrogen dioxide concentration of $15 \mathrm{ppb}$ was associated with an approximately $40 \%$ increase in the occurrence of lower respiratory symptoms. The increase in symptoms was greater in girls than in boys. There was no detectable effect of nitrogen dioxide exposure on pulmonary function in these children.
Unit, City Hospital Nottingham NG5 1PB J Britton

Reprint requests to: Dr J Britton 
These studies provide further evidence that adverse effects on respiratory health occur at currently permitted levels of outdoor pollution, and at levels of indoor pollution that occur in many households. The findings for indoor pollution are not entirely unexpected because several studies have linked domestic nitrogen dioxide pollution with respiratory health in children, ${ }^{16}$ though few have measured nitrogen dioxide directly. The wider importance of the study is perhaps that it identifies respiratory morbidity that is open to intervention as the prevention of pollution by inadequately ventilated heat sources should be relatively simple. The findings on outdoor pollution were also predictable, principally because any pollution limit other than zero is unlikely to prevent biological effects completely, but also because improvements in the quality of exposure and outcome measurements, and in statistical methods, will tend to uncover small biological effects that might have been missed two or three decades ago. In an invited commentary on the Barcelona study $\operatorname{Corn}^{17}$ argued that measurable effects of low level pollution in a sensitive or susceptible subgroup of the population are to be expected, and that pollution standards that would ensure zero risk to the entire population are unrealistic. The effects of outdoor pollution must, however, be kept under scrutiny, and permitted levels periodically reappraised to take account of changes in patterns of pollution and in the prevalence of diseases particularly susceptible to the effects of exposure to pollution. Studies of this nature are an essential part of that process; they need to be extended to examine the effects of pollution on people with asthma, and to assess the interactions between the effects of different pollutants and meteorological variables.

Determining what is an acceptable level of pollution in public health terms will never be easy, and converting these decisions into policy even less so. At a superficial level, however, the Barcelona data suggest that a reduction in permitted sulphur dioxide concentrations by $25 \mu \mathrm{g} / \mathrm{m}^{3}$ would decrease hospital admissions for chronic obstructive lung disease by about $5 \%$, and that similar benefits might be achieved by relatively small restrictions in permitted concentrations of other pollutants. Perhaps the time has come to explore the costs and benefits of such restrictions in more detail.

1 Holland WW, Bennett AE, Cameron IR, Florey C du V, Leeder SR, Schilling RSF, et al. Health effects of particulate pollution: reappraising the evidence. Am Epidemiol 1979;110:527-659.

2 Lippmann $M$. Health effects of ozone: a critical review. Journal of the Air Pollution Control Association 1989; 39:672-95.

3 Levy D, Gent M, Newhouse MT. Relationship between acute respiratory illness and air pollution levels in an industrial city. Am Rev Respir Dis 1977;116:167-73.

4 Melia RJW, Florey C du V, Swan AV. Respiratory illness in British schoolchildren and atmospheric smoke and sulphur dioxide 1973-7. J Epidemiol Comm Health 1981;35 161-7.

5 Samet JM, Speizer FE, Bishop Y, Spengler JD, Ferris BG. The relationship between air pollution and emergency room visits in an industrial community. Journal of the Air Pollution Control Association 1981;31:236-40.

6 Goldstein IF, Weinstein AL. Air pollution and asthma effects of exposures to short-term sulfur dioxide peaks. Environ Res 1986;40:332-45.

7 Bates DV, Sizto R. The Ontario air pollution study: identification of the causative agent. Environ Health Perspectives 1989;79:69-72.

8 Dales RE, Spitzer WO, Suissa S, Schechter MT, Tousignant $\mathrm{P}$, Steinmetz N. Respiratory health of a population living downwind from natural gas refineries. Am Rev Respir Dis 1989;139:595-600.

9 Koo LC, Ho JHC, Matsuki H, Shimizu H, Mori T, Tominaga S. Personal exposure to nitrogen dioxide and its association with respiratory illness in Hong Kong. Am Rev association with respiratory ill

10 Schwartz J, Zeger S. Passive smoking, air pollution and acute respiratory symptoms in a diary study of studen nurses. Am Rev Respir Dis 1990;141:62-7.

11 Pope CA, Dockery DW, Spengler JD, Raizenne ME. Respiratory health and PM10 pollution. Am Rev Respir Dis 1991;144:668-74.

12 Sunyer J, Anto JM, Murillo C, Saez M. Effects of urban air pollution on emergency room admissions for chronic obstructive pulmonary disease. Am J Epidemiol 1991;134: 277-86.

3 Neas LM, Dockery DW, Ware JH, Spengler JD, Speize FE, Ferris BG. Association of indoor nitrogen dioxide with respiratory symptoms and pulmonary function in children. Am J Epidemiol 1991:134:204-19.

14 Conseil de l'Europe. Directive du conseil 80/779/CEE. Journal officiel des communautes europeennes. 1980;1229. 30-48.

5 World Health Organisation. Air quality guidelines for Europe. Copenhagen: World Health Organisation, 1987. (WHO regional publications, European series 23.)

16 Samet JM, Marbury MC, Spengler JD. Respiratory effects of indoor air pollution. $J$ Allergy Clin Immunol 1987;79. of indoor

17 Corn M. Invited commentary on "Effects of urban air pollution on emergency room admissions for chronic obstructive pulmonary disease." Am J Epidemiol 1991 134:287-9. 